\title{
A Ultra-Light High Gain Circularly-Polarized Antenna Array for Mobile Satellite Terminals
}

\author{
Jianquan Huang \\ School of Electronics Information and Electrical engineering, \\ Xiangnan University, Chenzhou 423000, China \\ Email: huangjq00@163.com \\ Wei Lin and Y. Jay Guo \\ Global Big Data Technologies Centre, \\ University of Technology Sydney, Ultimo 2007, Sydney, Australia, \\ Email:Wei.Lin@uts.edu.au, Jay.Guo@uts.edu.au
}

\begin{abstract}
A ultra-light, compact, high gain $16 \times 6 \mathrm{CP}$ antenna array for $\mathrm{Ku}$ band mobile satellite applications is presented in this paper. The 96-element array consists of $242 \times 2$ CP sub arrays fed by a substrate-integrated-waveguide (SIW) network. Two essential and innovative techniques were adopted in this design. First, in order to achieve the ultra-light weight, the radiation patches were etched on the Polyimide film supported by a patterned foam. A piece of thin SIW network was designed to feed the radiators. The total weight of the fabricated array prototype is only 66.5 gram and profile is low as $0.05 \lambda_{0}$. Second, a sequential rotation (SQR) feeding technique was applied to the aperture fed $2 \times 2 \mathrm{CP}$ sub array, which realized more than three times bandwidth enhancement than the direct (non-SQR) feeding approach. In addition, the measured results show the CPoperational bandwidth is $700 \mathrm{MHz}$ from 11.55 to $12.25 \mathrm{GHz}$. The peak realized gain is $26.4 \mathrm{dBic}$ and gain variation is stable (less than $3 \mathrm{~dB}$ ) cross the entire operating bandwidth. With ultra-light and high gain, it is an excellent candidate for $K u$ band satellite applications.
\end{abstract}

Index Terms - aperture fed patch antenna, CP antenna array, Ku band satellite application, low profile, SIW feed network, ultra-light.

\section{INTRODUCTION}

Lightweight, low-profile, compact and high gain $\mathrm{CP}$ antenna array is highly desired in mobile satellite applications, in particular, the popular $K u$ band satellite $\mathrm{TV}$ and telecommunication applications worldwide [1], [2]. Traditional satellite antennas like the parabolic reflector antennas (dishes) are bulky and heavy. For example, a typical commercial $\mathrm{Ku}$ band dish antenna occupies the diameter of $65 \mathrm{~cm}$ and weighs 7 KGS [3]. CP antenna arrays mounted on mobile objects as earth vehicles, air planes or ocean vessels are preferred to be compact, low-profile and light-weight for the ease of satellite tracking [4].

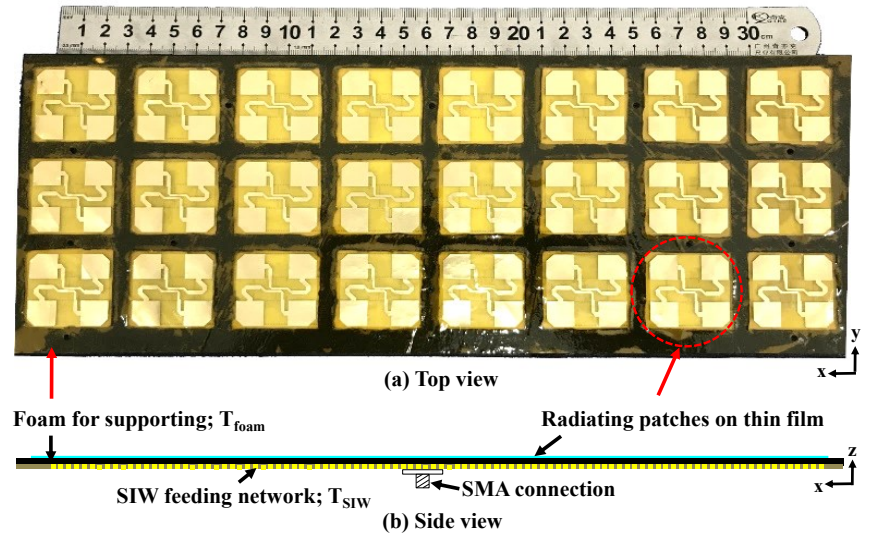

Fig. 1. Configuration of the compact, ultra-light and low profile CP $6 \times 16$ aperture-coupled patch array.

Many efforts have been made on low-profile and lightweight CP antenna arrays based on either patch radiators [5] [7] or slot radiators [8] - [10]. However, it is challenging to achieve all the characteristics of low profile, light-weight, high efficiency and sufficient bandwidth at the same time. For instance, the reported designs in [5] - [9] require at least two layers of PCB (printed-circuit-board) substrates with the minimum profile of $0.12 \lambda_{0}$. To further reduce the profile, one design in [10] adopts the $4 \times 4$ slot radiators etched on a SIW cavity feed network. Although the profile is only $0.03 \lambda_{0}$ due to the use of single layer of PCB substrate, the achievable bandwidth is only $1 \%$ and it is hard to be expanded for larger scale arrays.

Our developed compact CP antenna array shown in Fig. 1 achieves low-profile $\left(0.05 \lambda_{0}\right)$, ultra-light weight (66.5 gram), high gain $(26.4 \mathrm{dBic})$, high efficiency $(65 \%)$, large scale $(16 \times$ 6) and decent operating bandwidth $(700 \mathrm{MHz}$ from 11.55 to $12.25 \mathrm{GHz}$ or $6 \%$ fractional bandwidth) at the same time. It is an ideal candidate to be mounted on moving mobile terminals for $K u$ band satellite applications. 


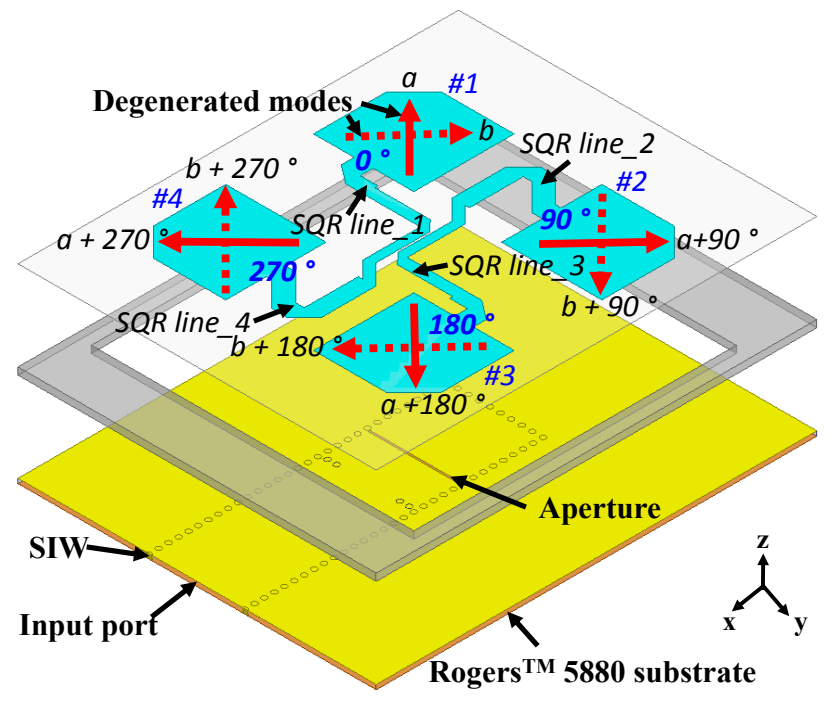

Fig. 2. Details of the single $2 \times 2 \mathrm{CP}$ sub-array design and demonstration of the operating principle.

\section{ANTENNA DESIGN AND PERformance}

The CP array prototype is shown in Fig. 1, which consists of three layers as the patch radiators, a supporting foam and a SIW feed network from top to bottom. The 96-element cornernotched patch radiators (24 sub arrays) were etched on a thin $(0.1 \mathrm{~mm})$ Polyimide film with the dielectric constant of 3, which is on the top. A $0.8 \mathrm{~mm}$ supporting foam is placed below the film with the square regions beneath the sub array removed. A SIW feed network with the thickness of $0.508 \mathrm{~mm}$ is located at the bottom. The overall size of the prototype is $340 \mathrm{~mm}\left(13 \lambda_{0}\right) \times 137 \mathrm{~mm}\left(5.3 \lambda_{0}\right) \times 1.408 \mathrm{~mm}\left(0.05 \lambda_{0}\right)$.

The detailed description of the $2 \times 2 \mathrm{CP}$ sub array is shown in Fig. 2. The 1 to 4 feed network is realized by the transition from a rectangular aperture on a SIW to four sequentiallyrotated microstrip lines. The excitation phases for the four patches are sequentially delayed. Consequently, the currents of the two degenerated modes on the corner-notched patch are rotating sequentially in a clockwise manner to form a lefthanded CP (LHCP) radiation in the broadside direction. Due to the SQR feeding technique, the realized operating bandwidth has increased more than three times than the direct feeding technique as discussed in [1].

The array prototype was fabricated and measured. The measured results agree reasonably with the simulated values as shown in Figs. 3 and 4. The measured $\left|\mathrm{S}_{11}\right|$ covers $750 \mathrm{MHz}$ from 11.55 to $12.3 \mathrm{GHz}$, which slightly shifts to the lower band from simulation. The measured overlapped impedance and AR bandwidth is $700 \mathrm{MHz}$ from 11.55 to $12.25 \mathrm{GHz}$. In addition, the measured realized gain values are stable (less than $3 \mathrm{~dB}$ ) across the entire operating bandwidth. Decent radiation patterns are also obtained with large crosspolarization level $(19 \mathrm{~dB})$ and good sidelobe level (lower than $-12 \mathrm{~dB})$. The above measured results show the developed antenna is a good candidate for many wireless applications, in particular, for the $k u$ band satellite systems.

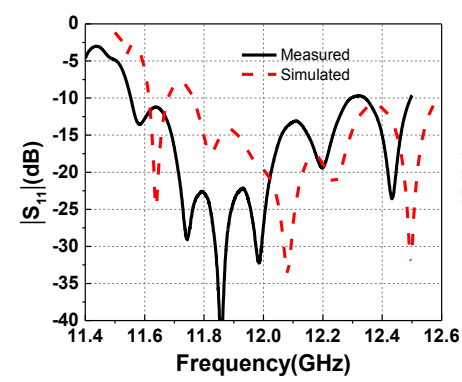

(a)

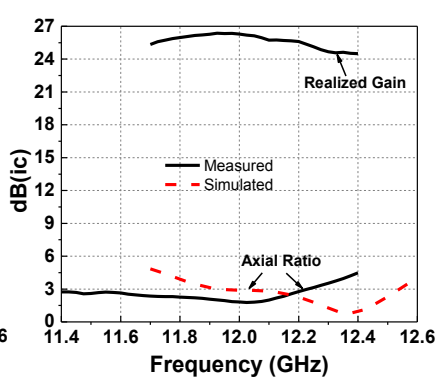

(b)
Fig. 3. Measured and simulated results. (a) $\left|S_{11}\right|$ as functions of the source frequency; and (b) Axial ratio and realized gain values as functions of the source frequency.

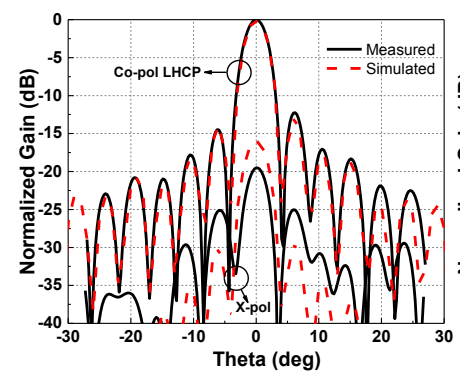

(a)

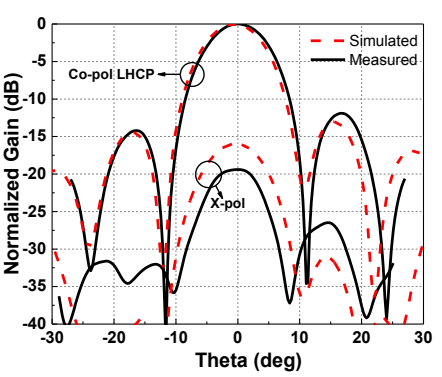

(b)
Fig. 4. Measured and simulated radiation patterns. (a) $\varphi=0^{\circ}$; and (b) $\varphi=90^{\circ}$.

\section{References}

[1] J. Q. Huang, W. Lin, F. Qiu, C. Jiang, D. Lei, and Y. J. Guo, "A low profile, ultra-lightweight, high efficient circularly-polarized antenna array for $\mathrm{Ku}$ band satellite applications," IEEE Access, vol. 5, pp. 18356-18365, Sep. 2017.

[2] J. Q. Huang, F. Qiu, W. Lin, Z. H. Tang, D. J. Lei, M. Yao, Q. X Chu, and Y. J. Guo, "A new compact and high gain circularly-polarized slot antenna array for $\mathrm{Ku}$ band mobile satellite TV reception," IEEE Access, vol. 5, pp. 6707-6714, May. 2017.

[3] Data Sheet of the $65 \mathrm{~cm} \mathrm{Ku}$ Band Offset Dish Antenna, Fortec Star Inc, Application Note [Online]. Available: http://www.viasatelital.com.

[4] W. Lin and H. Wong, "Circularly polarized conical beam antenna with very thin profile and wide bandwidth," IEEE Trans. Antennas Propag,, vol. 62, no. 12, pp. 5974-5982, Dec, 2014.

[5] Y. Li, Z. N. Chen, X. Qing, Z. Zhang, J. Xu and Z. Feng, “Axial ratio bandwidth enhancement of $60-\mathrm{GHz}$ substrate integrated waveguide-fed circularly polarized LTCC antenna array," IEEE Trans. Antennas Propag., vol. 60, no. 10, pp. 4619-4626, Oct. 2012.

[6] H. Sun, Y. X. Guo and Z. Wang, "60-GHz circularly polarized U-Slot patch antenna array on LTCC," IEEE Trans. Antennas Propag., vol. 61, no. 1, pp. 430-435, Jan. 2013.

[7] J. Wu, Y. J. Cheng and Y. Fan, "Millimeter-wave wideband highefficiency circularly polarized planar array antenna," IEEE Trans. Antennas Propag., vol. 64, no. 2, pp. 535-542, Feb.. 2016.

[8] D. F. Guan, C. Ding, Z. P. Qian, Y. S. Zhang, Y. J. Guo and K. Gong "Broadband high-gain SIW cavity-backed circular-polarized array antenna," IEEE Trans. Antennas Propag., vol. 64, no. 4, pp. 1493-1497, Apr., 2016.

[9] Y. Lang, S. W. Qu and J. X. Chen, "Wideband Circularly Polarized Substrate Integrated Cavity-Backed Antenna Array," IEEE Antennas Wireless Propag. Lett., vol. 13, pp. 1513-1516, 2014.

[10] Z. C. Hao, X. Liu, X. Huo and K. K. Fan, "Planar high-gain circularly polarized element antenna for array applications," IEEE Trans. Antennas Propag., vol. 63, no. 5, pp. 1937-1948, May, 2015. 